\title{
Network Analysis in Tourism Distribution Channels
}

\author{
Dr. Ananda S Jeeva \\ School of Information Systems \\ Curtin University \\ Perth, Australia \\ a.jeeva@curtin.edu.au
}

\author{
Mai T T Tran \\ School of Information Systems \\ Curtin University \\ Perth, Australia \\ t.tran45@postgrad.curtin.edu.au
}

\begin{abstract}
Application of Network Analysis in tourism research is relatively new, especially in the study of tourism distribution channels. Network Analysis is employed to investigate the structure and pattern of relationships between actors in a network. This paper applies Network Analysis with ORA software to analyze tourism distribution channels. The results of the research show the pattern of the network between tour operators and travel agencies and between tour operators. Network Analysis also reveals the cooperation and cohesion of the network as well as the network dynamics between the case study tour operator and its travel agencies over a period of time.
\end{abstract} study

Keywords-tourism distribution network; network analysis; case

\section{INTRODUCTION}

Social network analysis or network analysis has been applied into a tourism case study to investigate the relationships between entities or stakeholders in tourism studies. In particular, network analysis has been utilized to investigate relationships between tourists' groups, stakeholders in the tourism destination, web connections between tourism companies, and stakeholders in sustainable tourism packages.

This paper has applied network analysis with the use of ORA software to examine the tourism distribution channels and inter-relationships. This network analysis approach is applied within a case study of a tour operator in Vietnam. Data was collected from the tour operator and its partners.

\section{BACKGROUND}

\section{A. Tourism Distribution channels}

Tourism distribution channel is a narrower definition of tourism supply chain, which focuses on the distribution and marketing activities [1], [2]. Distribution channels in tourism consist of service providers, tour operators, retail travel agent and customers [3]. Intermediaries such as travel agencies and tour operators can bring sellers (service providers) and buyers (tourists) together and then create a tourism network market.

Tour operators or tour packagers can also be viewed as wholesalers in the tourism distribution channels whereas travel agencies are considered as retailers. Tour operators and travel agencies are intermediaries linking tourists with service suppliers. They play the role of professional sources of information for customers; and tourists tend to rely on these intermediaries for information about tour packages [4], [5].

\section{B. Network analysis}

Network or social network is defined as a specific type of relation or relations linking a set or sets of actors (persons, objects or events) [6]. There are many kinds of network e.g: whole network, ego network, one-mode network, two-mode network and multi-mode network. This paper focuses on twomode network between tour operators and travel agencies and one-mode network of tour operators and also dynamics of network between one tour operator and its partners.

Network analysis has been applied in many researches and studies and it has become more popular since the 1990s. These network analysis emphasized on the relationship and integration of actors. Network analysis is an approach and set of techniques used to study the exchange of resources among actors in a network. It reveals the pattern of relationships between actors, the availability of resources and the exchange of resources between these actors [7]. The network concept and network analysis techniques can be used as a tool for conceptualizing, visualizing and analysing the complex sets of relationships. It can examine both the content and the pattern of relationships in order to determine how and what resources flow from one actor to another [7].

\section{LITERATURE REVIEW}

\section{A. Network analysis in tourism studies}

There are different methods to examine the relationships between entities within tourism distribution channels. For example, using social exchange theory and resource dependence theory to examine the relationship between hotels and restaurants (both are service providers in tourism) [8]; strategic contingency theory to find the relationship between tourism organizations in the exchange of critical resources [9]; analyzing the distribution strategies of major carriers [5], interview with secondary research of small and medium tourism enterprises and tour operators [10], statistics data analysis with Likert-types questionnaire of hotels and travel agencies [11], and interviewing travel agencies and tour operators [12]. However, there is limited published literature utilizing network analysis to analyze tourism distribution networks/channels.

In this research paper network analysis has been applied into tourism studies to investigate the relationships in tourism SC. One of the early studies using network analysis in tourism was [13] to examine the relationship of tourists' groups. Later, there are many authors applied network analysis in analyzing 
the relationships in tourism industry. There are two main streams of application of network analysis into tourism research: using network to understand the evolution of business networks, analyze inter-organizational relationships; and applying network analysis in tourism policy study [14]. The first streams can be recorded with researches of [15], [16], [17]. The second stream can be seen in the researches of [18], [19], and [20]. The network of entities in tourism distribution channels can be seen as business networks; therefore, the research of relationships along tourism distribution channels belongs to the first stream. However, there are few publications using network analysis to analyze the relationships in the first stream or the business network, including tourism distribution channels.

\section{B. Network analysis in analysing distribution channel/network}

Network analysis has been applied in numerous fields and areas such as shareholding network, community structure, political and policy network, social movements, and economics [21]. In addition, [22] it is suggested that: "the study of inter-organizational relations in marketing channels should probably take the form of analyzing networks instead of dyads". Moreover, [23] it is claimed that the dynamic distribution network could be analyzed by using network analysis to have "a deeper perspective of what takes place in channels of distribution overtime". However there are a few publications utilizing network analysis to study distribution network, especially the dynamics of distribution networks.

It is [23] also claimed that distribution channels can employ the "so-called industrial network approach" to analyze. In addition, network analysis has been employed in the research of heroin distribution network [24] or between borrowing banks and lending banks in bank network in Italy [25]. These researches are illustrations of the probability of utilizing network analysis in studying relationships in distribution networks. However, these researches have not considered the dynamics of the network over a period of time. This paper has collected data over a 8 week period to analyze changes in the network dynamics.

\section{METHODOLOGY}

This paper employs case study as the research strategy. A case study of tour operators and travel agencies in Vietnam of a specific tour package to Halong Bay and a specific tour operator is used to investigate tourism distribution channels. The evidence for the relationship between the channels is collected from websites of actors, interview and archival data of the tour operator.

Data collection: Data for this case study strategy was collected from multiple resources, including secondary data and primary data..

The network of travel agencies and tour operator is based on the web-link between those entities. 12 tour operators were chosen as they provide a similar tour package (deluxe package) with the case study tour operators. 50 travel agencies were chosen from the list of agencies that most frequently introduced customers to the case study tour operator.
Data was also collected by archival data (recording customers introducing from travel agencies) to examine the relationship between the case study tour operator and travel agencies. Staff of the case study tour operator was interviewed to confirm the relationships.

This research paper utilises ORA software to analyse the network. This software provides the visualization of the network as well as network measures. The software also analyses the dynamics of the network.

\section{RESULT AND DISCUSSION}

\section{A. Visualization of network}

The network of web-links between travel agencies and tour operators is visualized as Figure I . It shows little connection or linkage between tour operators as explanation of staff of the case study tour operator. Some travel agencies are only connected to some specific tour operators and do not link with others.

\section{B. Network measurement}

\section{Network of tour operators:}

The network shows connectedness of 0.045 and high fragmentation $(0.955)$, which reveals a high proportion of disconnected nodes. The low density (0.045) in the network shows the loose connections between tour operators in the network.

Network centralization index shows how centralized the degree of the network is. This low index (0.164) proves the low concentration of the network. This low index also reflects a little variability of node centrality, or in another words, there is not a great difference between the largest and smallest actor level indices in centrality degree.

The network has a value of 0.333 in interdependence index; it means it has $33.3 \%$ of links that are reciprocal. This index also reveals the low moderate degree of cohesion in the population of network.

Network closeness centralization index is used to examine the connectivity and reachability degree of network. Network closeness centralization of tour operators is 0.029 , which reflects the loose connection between actors or low degree of reachability in the network.

All these indicators indicate the very limited degree of collaboration or cooperation among tour operators in the network.

\section{Network of travel agencies and tour operators:}

The low moderate level of network density $(0.418)$ reflects the low moderate social level of organizational cohesion. However, in order to understand this indicator, it is necessary to understand the relation to the size of the network and the type of work performed [26]. In this case study, the travel agencies were chosen from a list of agencies that introduce customers to the case study tour operator. Hence, it can help to increase this index. Moreover, the connection between tour operators and travel agencies create the tourism distribution 
channels and its cooperation or integration is critical for the success of the tour package. Thus, it might be high expectation of cooperation and integration between tour operator and travel agent, which might lead to high level of organizational cohesion and high density. However, the index is in low moderate level, therefore, the network of tour operators and travel agencies in this case study might have a low moderate level of cohesion.

The high degree of network centralization (2.644) proves the fact that there are one-way links between travel agencies and tour operators' websites. This fact was also proved when the tour operator staffs were interviewed. The staff confirmed that they do not introduce any customers to any travel agencies.

Taking number of deluxe cabins of each cruise as attribute for the tour operator to examine how capacity of cruises affects the centrality index of tour operators in the network. The capacity of cruises is taken as the weight of link between travel agencies and tour operators. It means the maximum cabins can be utilized or introduced by travel agencies. In the binary network, HLG has highest centrality index whereas EmC achieves this highest in the valued network. Centrality of a node show how "active" the node is, the higher value means the more active node. It also "displays the ability to access information through links connecting other nodes" [26]. It means EmC becomes higher ability to access information in the value network. Therefore, the capacity of cruise actually has effect on the activity of the network.

\section{Position of Halong Glory in the network:}

The average level of sharing node of travel agents between tour operators and HLG is 13.833 with the maximum level of 22. EmC is the most important competitor with HLG.

HLG records the highest indicators of capability and centrality ( 0.9933 and 0.64 respectively). These indices reveal that HLG is more competitive than other tour operators [26]. The high degree of centrality of EmC, CC and EC means that the large amount of travel agencies connected to HLG is also connected to those cruises. Therefore, those cruises are the main competitors of HLG.

\section{Dynamic egocentric network:}

The dynamic network between HLG and travel agencies over 8 weeks is analysed to see how the network changed during the 8 weeks (June and July, 2013). The density indices including non-weighted and weighted density were taken into consideration to analyse the egocentric network. Figure II shows the dynamics of the network.

Figure II shows an increasing trend of linkage numbers over the 8 weeks. This means HLG had increased connections with travel agencies and more agencies introducing customers to HLG. Figure II also shows the density of the network in terms of weighted and unweighted network. The non-weighted density reflects exactly the links count in the network, and it also shows the instability of the connections of the network. Moreover, while the density of non-weighted network shows the increasing trend, the density of the weighted network does not show a similar pattern. The pattern of weighted density means the average strength of ties of the network. The average strength of ties over 8 weeks is quite low and not proportional to the increasing number of connections between HLG and travel agencies.

\section{LIMITATIONS AND RECOMMENDATIONS}

The paper has investigated the tourism distribution network with 50 travel agencies and 12 tour operators, which provide deluxe tour package to Halong Bay. However, the operation of other types of cruises also affects the competition in the market as well as the network dynamics between travel agencies and tour operators. Thus, in the future, all tour operators, travel agencies and suppliers should be analyzed and visualized in the tourism distribution network. Moreover, the network of travel agencies and tour operators was the binary network and has not taken into account the strength of relationships between travel agencies and tour operators. Future research should be more detail in the strength of the relationship (in term of the number customers introducing to tour operators) between these entities.

\section{CONCLUSIONS AND IMPLICATIONS}

Despite the prominent application of network analysis in tourism study and the suggestions of using network analysis in distribution networks, network analysis in tourism distribution channels has not been employed by previous researchers. This paper has applied network analysis into tourism distribution channels with a case study approach.

The network reveals the loose connections, low degree of cohesion in population and very limited degree of collaboration or cooperation among tour operators in the network. There are one-way link between travel agencies and tour operators in the website network of travel agencies and tour operator. In addition, the capacity of cruise has influence on the network in term of identifying the most activity node of the network: the higher capacity cruise will become more active in the network. Cooperation or integration in tourism distribution channels is very important when it "could ensure that all actors achieve the best possible outcomes" [1]. Hence, the lack of cooperation in the network of tour operators and the network between tour operators and travel agencies should be taken into consideration of both entities in the distribution channels. In term of a case study of HLG, this tour operator has more competition than other tour operators in the network. Network analysis also identified the main competitors of the tour operator. Thus, the tour operators might focus on strategies to stand out of main competitors or create more influence on their travel agencies, which also has connections with the main competitors, in order to achieve more customers to maximize the capacity of its cruises. The dynamics of network between HLG and travel agencies reveals an unstable increasing trend of the number connections between the tour operator and travel agencies and the low degree of average strength of ties over the period of time. However, it is necessary to investigate the reason of the on-off relationships with some travel agencies as well as characteristics of the tour package such as seasonal factors. 


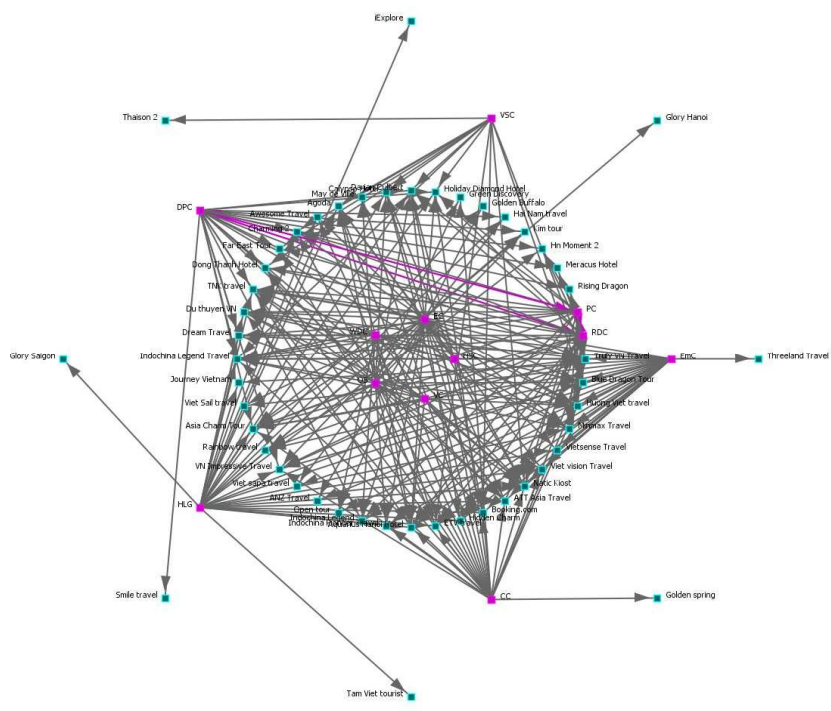

FIGURE I . NETWORK OF TRAVEL AGENCIES AND TOUR OPERATORS

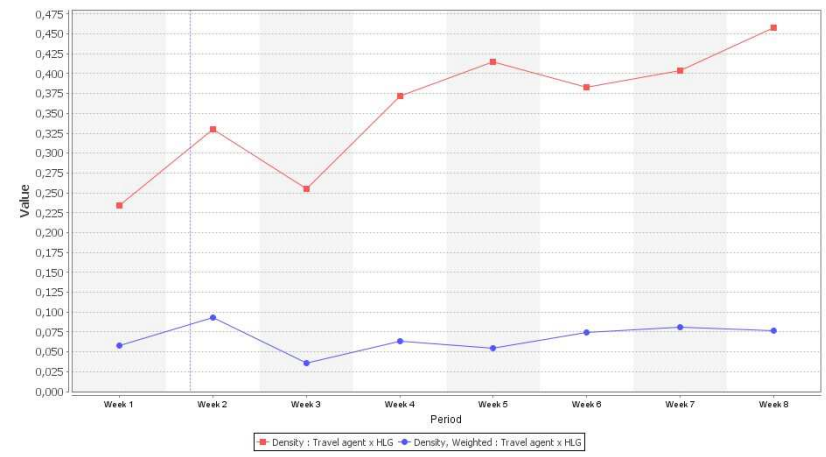

FIGURE II. DYNAMICS OF NETWORK BETWEEN HLG AND ITS TRAVEL AGENCIES

\section{REFERENCES}

[1] Song, Haiyan, J. Y. Liu, and G. Z. Chen. "Tourism Value Chain Governance: Review and Prospects." J. Travel Res. 52, no. 1 (2013): 1528.

[2] Zhang, X., H. Song, and G. Q. Huang. "Tourism Supply Chain Management: A New Research Agenda." Tourism Management 30, no. 3 (2009): 345-58.

[3] Bitner, M. J., B. H. Bitner, and Booms. "Trends in Travel and Tourism Marketing: The Changing Structure of Distribution Channels." Journal of travel research 20, no. 4 (1982): 39-44.

[4] Bieger, T., and C. Laesser. "Information Sources for Travel Decisions: Toward a Source Process Model." Journal of Travel Research 42, no. 4 (2004): 357-71.

[5] Alamdari, F. "Regional Development in Airlines and Travel Agents Relationship." J. Air Transp. Manag. 8, no. 5 (2002): 339-48.

[6] Wasserman, Stanley. Social Network Analysis : Methods and Applications / Stanley Wasserman, Katherine Faust. edited by Katherine Faust Cambridge.New York : Cambridge University Press, 1994.

[7] Haythornthwaite, Caroline. "Social Network Analysis: An Approach and Technique for the Study of Information Exchange." Library \& Information Science Research (1996).
[8] Shi, Xinping, and Ziqi Liao. "Managing Supply Chain Relationships in the Hospitality Services: An Empirical Study of Hotels and Restaurants." International Journal of Hospitality Management 35 (2013): 112-21.

[9] Ford, R. C., Y. C. Wang, and A. Vestal. "Power Asymmetries in Tourism Distribution Networks." Ann. Touris. Res. 39, no. 2 (2012): 755-79.

[10] Bastakis, C., D. Buhalis, and R. Butler. "The Perception of Small and Medium Sized Tourism Accommodation Providers on the Impacts of the Tour Operators' Power in Eastern Mediterranean." Tourism Manage. 25, no. 2 (2004): 151-70.

[11] Medina-Muñoz, Diego R.; Juan M. García Falcón; Rita D. MedinaMuñoz. "Building the Valuable Connection: Hotels and Travel Agents." The Cornell hotel and restaurant administration quarterly 43, no. 3 (2002): 46-52.

[12] Pan, Grace Wen. "A Theoretical Framework of Business Network Relationships Associated with the Chinese Outbound Tourism Market to Australia." Journal of Travel \& Tourism Marketing 14, no. 2 (2003/11/04 2003): 87-104.

[13] Stokowski, P.A. Leisure in Society: A Network Structural Perspective. London: Mansell, 1994.

[14] Dredge, D. "Policy Networks and the Local Organisation of Tourism." Tourism Management 27, no. 2 (2006): 269-80.

[15] Scott, Noel; Rodolfo Baggio; Chris Cooper "Network Analysis Methods for Modeling Tourism Inter-Organizational Systems,." In Tourism Sensemaking: Strategies to Give Meaning to Experience, edited by Arch G. Woodside. Advances in Culture, Tourism and Hospitality Research, 177-221: Emerald Group Publishing Limited, 2011.

[16] Costa, L. D., and R. Baggio. "The Web of Connections between Tourism Companies: Structure and Dynamics." Physica A 388, no. 19 (2009): 4286-96.

[17] Pavlovich, K. "The Evolution and Transformation of a Tourism Destination Network: The Waitomo Caves, New Zealand." Tourism Management 24, no. 2 (2003): 203-16.

[18] Baggio, Rodolfo. "Network Science: An Interdisciplinary Contribution to Tourism Studies." In Competence Center in Tourism Management and Tourism Economics (TOMTE). the Free University of Bolzano, Brunico, Italy, 2009.

[19] Baggio, R., and C. Cooper. "Knowledge Transfer in a Tourism Destination: The Effects of a Network Structure." Service Industries Journal 30, no. 10 (2010): 1757-71.

[20] Watts, Michelle. "Collaborative Implementation Network Structures: Cultural Tourism Implementation in an English Seaside Context." Systemic practice and action research 22, no. 4 (2009): 293-311.

[21] Carrington, Peter J. The Sage Handbook of Social Network Analysis / Edited by John Scott and Peter J. Carrington. Social Network Analysis. edited by John Scott and Peter J. Carrington London: London : SAGE Publications, 2011.

[22] Achrol, Ravi Singh, Torger Reve, and Louis W. Stern. "The Environment of Marketing Channel Dyads: A Framework for Comparative Analysis." The Journal of Marketing 47, no. 4 (1983): 5567.

[23] Andersson, Per. "Analysing Distribution Channel Dynamics: Loose and Tight Coupling in Distribution Networks." European Journal of Marketing 26, no. 2 (1992): 47-68.

[24] Natarajan, Mangai. "Understanding the Structure of a Large Heroin Distribution Network: A Quantitative Analysis of Qualitative Data.". Journal of Quantitative Criminology 22, no. 2 (2006/06/01 2006): 17192.

[25] Iori, Giulia, Giulia De Masi, Ovidiu Vasile Precup, Giampaolo Gabbi, and Guido Caldarelli. "A Network Analysis of the Italian Overnight Money Market." Journal of Economic Dynamics and Control 32, no. 1 (2008): 259-78.

[26] Carley, Kathleen M., and Dave Columbus. Basic Lessons in Ora and Automap 2011. Institute of Software Research. School of Computer Science. Carnegie Mellon University, 2011. 